\title{
Atividade Alelopática do filtrado de Cultura Produzido por Fusarium solani ${ }^{1}$
}

\author{
Allelopathic Activity of Culture Filtrate Produced by Fusarium solani
}

SOUZA FILHO, A.P.S. ${ }^{2}$ e DUARTE, M.L.R. ${ }^{2}$

\begin{abstract}
RESUMO - As plantas daninhas se constituem no principal problema a impor limitação à exploração da agropecuária nas áreas tropicais. Entretanto, o controle químico dessas plantas tem gerado insatisfações de ordem social, quer porque contaminam as fontes de recursos naturais ou por comprometerem a qualidade dos alimentos da dieta dos animais, em geral, e dos humanos, em particular. Os objetivos deste trabalho foram identificar e caracterizar a atividade alelopática do filtrado de cultura produzido pelo fungo Fusarium solanif. sp. pipers. Foram avaliados os efeitos das toxinas, nas concentrações de 1,0 e 4,0\%, sobre a germinação de sementes e o desenvolvimento da radícula e do hipocótilo das plantas daninhas malícia (Mimosa pudica) e mata-pasto (Senna obtusifolia). Os resultados mostraram presença de atividade alelopática inibitória, com variações de acordo com a concentração e a planta receptora. A intensidade dos efeitos inibitórios induzidos pelo extrato esteve positivamente associada à concentração, com efeitos mais intensos verificados a 4,0\%. Independentemente da concentração e do bioensaio, a espécie malícia se mostrou mais sensivel aos efeitos do filtrado da cultura. O desenvolvimento da radícula foi o fator da planta mais intensamente inibido. Os resultados indicam a existência de potencial de utilização da toxina produzida pelo fungo, como fonte alternativa no controle de plantas daninhas, o que justifica estudos mais avançados.
\end{abstract}

Palavras-chave: alelopatia, inibição, germinação, radícula, hipocótilo, toxinas.

\begin{abstract}
Weeds are a major problem limiting agriculture and cattle raising activities in the tropics. Current chemical control measures have raised environmental concerns due to their potential of contaminating natural resources and compromising the quality of animal feed. The objective of this paper was to identify and characterize the potential allelopathic activity of Fusarium solani $f$. sp. pipers culture filtrate. The effects of the toxin were analyzed at $1 \%$ and $4 \%$ concentration, on seed germination and radicle and hypocotyl elongation of the weeds Mimosa pudica and Senna obtusifolia. The results showed potential inhibitory allelopathic activity of the Fusarium culture filtrate, varying according to concentration and receiving plants. The intensity of the inhibition effects promoted by the extracts was clearly associated to concentration, with the major effect being observed at 4\%. Regardless of concentration and bioassays, Mimosa pudica was more sensitive to the toxin effects of the culture filtrate. Radicle elongation was more intensely inhibited by the culture filtrate toxins. The results showed potential for the use of the toxins produced by Fusarium solani $f$. sp. pipers, as an alternative source to control weeds. However, further studies should be carried out.
\end{abstract}

Keywords: allelopathy, inhibition, germination, radicle, hypocotyl; toxins.

O desenvolvimento da atividade agrícola nos trópicos tem sido, em muito, limitado pelo aparecimento de comunidades de plantas daninhas extremamente agressivas e diversificadas. O controle dessas plantas é de fundamental importância para a lucratividade e o desempenho da atividade agropecuária nessas regiões. Entretanto, os atuais métodos de controle - especialmente os que envolvem o uso de produtos químicos sintéticos, como os herbicidas - têm apresentado exaustão, sobretudo porque tem havido redução na eficiência dos produtos disponiveis no mercado, principalmente pelo crescente aparecimento de

Recebido para publicação em 9.2.2006 e na forma revisada em 27.2.2007.

Eng.-Agr. Dr., Embrapa Amazônia Oriental, Trav. Dr. Enéas Pinheiro, S/N, 66095-100 Belém-PA. 
biótipos de plantas daninhas resistentes a esses produtos (Christoffoleti et al., 1994; Jasieniuk et al., 1996). Heap (1999) menciona que no mundo ocorrem, a cada ano, nove novos casos de plantas daninhas resistentes a herbicidas e que existem mais de 230 biótipos resistentes a diferentes classes de herbicidas, em 42 países. No Brasil, a resistência de plantas daninhas aos herbicidas disponíveis no mercado já foi relatada para as espécies picão-preto (Bidens pilosa), capim-colchão (Digitaria ciliares), capim-marmelada (Brachiaria plantaginea) e amendoim-bravo (Euphorbia heterophylla) (Lopes-Ovejero et al., 2005; Vidal et al., 2005; Christoffoleti, 2001; Vidal, 1997).

Paralelamente, o emprego de produtos sintéticos indicados para controle dessas plantas tem fomentado insatisfações de ordem social, mormente por elas poluírem os recursos naturais, porem em risco a vida silvestre e comprometerem a qualidade dos alimentos que fazem parte da dieta humana (Anaya, 1999).

Nos últimos anos, esforços têm sido desenvolvidos no sentido de encontrar novas fontes químicas para servir de base para obtenção de novos produtos ou mesmo para uso direto como bioerbicida. Entre essas alternativas, ênfase foi dada às plantas, como se pode constatar em trabalhos de Romagni et al. (2000a, b) e Duke et al. (2000).

Outra fonte que tem sido explorada com esse fim são as toxinas produzidas por fungos patogênicos de plantas. Muitos patógenos produzem substâncias tóxicas, as quais são responsáveis por muitos dos efeitos nocivos diretos nas espécies cultivadas. Essas toxinas podem agir sinergicamente com outras atividades do patógeno, desde que invada o tecido das plantas. Suas utilizações diretas como bioerbicidas ou como estrutura básica para o desenvolvimento de novas classes de herbicidas vêm recebendo cada vez mais atenção, não só por parte da comunidade científica, mas também pelas empresas que se dedicam à produção de defensivos agrícolas (Duke \& Abbas, 1995; Hoagland, 1990). Alguns trabalhos foram desenvolvidos nos últimos anos visando identificar e caracterizar a atividade biológica de toxinas produzidas por fungos (Gerwick et al., 1997; Strobel et al., 1991; Duke et al., 2002; Metha \& Brognin, 2000). Dentre as características importantes dessas toxinas, podem-se destacar a alta atividade específica e a alta seletividade, além de serem, ainda, biodegradáveis (Cutler, 1988). Tem merecido menção, ainda, o fato de essas toxinas possibilitarem a exploração de sítios moleculares de ação que ainda não foram cobertos pelos produtos sintéticos (Amagasa et al., 1994), o que permite o controle de plantas resistentes aos produtos de uso corrente.

A Amazônia, pela riqueza de sua biodiversidade, representada tanto por suas espécies botânicas como por microrganismos, pode fornecer excelentes fontes alternativas de toxinas produzidas por fungos fitopatógenos, como é o caso de Fusarium solani, fungo de solo promotor da podridão das raízes em pimenteira-do-reino (Piper nigrum), cultura de grande importância econômica para a região Amazônica.

Os objetivos deste trabalho foram identificar e caracterizar a atividade alelopática do filtrado de cultura produzido pelo fungo Fusarium solani sobre duas espécies de plantas daninhas.

Obtenção do filtrado de cultura: Um isolado de Fusarium solani f. sp. pipers, com grande habilidade de produzir toxinas, obtido de plantas de pimenteira-do-reino com sintomas de podridão das raízes, foi cultivado em placas de Petri com meio de cultura BDA (batata, 200 g; dextrose, 20 g; ágar, 15 d; água destilada, $1,0 \mathrm{~L}$ ) por sete dias. Discos de $10 \mathrm{~mm}$ de diâmetro, retirados da periferia das colônias, foram transferidos para recipientes de $250 \mathrm{~mL}$, contendo $50 \mathrm{~mL}$ do meio BS (batata, $200 \mathrm{~g}$; sucrose, $10 \mathrm{~g}$; água destilada, 1,0 L). A fim de estimular a produção de toxinas, os frascos foram envolvidos com papel-alumínio e mantidos estáticos, em ambiente de laboratório. As culturas foram filtradas em dupla gaze, para eliminação de micélio, e por um disco de papel-de-filtro qualitativo, usando-se funil de Buchner, sob vácuo, para eliminação de esporos (Duarte \& Archer, 2003). Posteriormente, o filtrado da cultura foi submetido ao processo de liofilização.

Análise da atividade alelopática: Os testes foram realizados nas concentrações de 1,0 e 4,0\%, utilizando-se o material liofilizado, tendo como eluente a água destilada. $\mathrm{O}$ bioensaio de germinação foi desenvolvido em condições controladas de $25^{\circ} \mathrm{C}$ de temperatura 
constante e fotoperíodo de 12 horas. A germinação foi monitorada em período de 10 dias, com contagens diárias e eliminação das sementes germinadas. Cada gerbox de $11 \mathrm{x} 11 \mathrm{x}$ $4 \mathrm{~cm}$ recebeu 40 sementes. O bioensaio de desenvolvimento da radícula e do hipocótilo foi desenvolvido em condições de $25{ }^{\circ} \mathrm{C}$ de temperatura constante e fotoperiodo de 24 horas. Cada gerbox recebeu três sementes prégerminadas, com aproximadamente três dias de germinação. Ao final do período de 10 dias de crescimento, mediram-se os comprimentos da radícula e do hipocótilo.

Em todos os bioensaios, cada gerbox recebeu $6,0 \mathrm{~mL}$ da solução aquosa contendo a toxina. A solução foi adicionada apenas uma vez, quando do início dos bioensaios, sendo, a partir de então, adicionada apenas água destilada, sempre que se fazia necessário. Como testemunha, utilizou-se a água destilada.

Plantas receptoras: Foram utilizadas as plantas daninhas malicia (Mimosa pudica) e mata-pasto (Senna obtusifolia).

Análise estatística: O delineamento experimental utilizado foi inteiramente casualizado, com quatro repetições, como modelo hierárquico com dois fatores: planta receptora e concentração. Os dados foram analisados pelo programa SAS (SAS, 1989).

Os resultados (Tabela 1) indicam efeitos alelopáticos inibitórios tanto da germinação das sementes como do desenvolvimento da radícula e do hipocótilo, com variações de intensidade em função de três aspectos: concentração da solução, espécie receptora e fator

Tabela 1 - Efeitos alelopáticos de toxinas produzidas pelo fungo Fusarium solani, sobre plantas daninhas de pastagens. Dados expressos em percentual de inibição em relação ao tratamento testemunha, água destilada

\begin{tabular}{|l|c|c|c|}
\hline \multirow{2}{*}{ Bioensaio } & Concentração & \multicolumn{2}{c|}{ Planta receptora } \\
\cline { 2 - 4 } & $(\%)$ & Malícia & Mata-Pasto \\
\hline \multirow{2}{*}{ Germinação } & 1,0 & $10,0 \mathrm{Ba}$ & $5,0 \mathrm{Bb}$ \\
\cline { 2 - 4 } & 4,0 & $40,0 \mathrm{Aa}$ & $21,0 \mathrm{Ab}$ \\
\hline Desenvolvimento & 1,0 & $50,0 \mathrm{Ba}$ & $35,0 \mathrm{Bb}$ \\
da Radícula & 4,0 & $64,0 \mathrm{Aa}$ & $51,0 \mathrm{Ab}$ \\
\hline Desenvolvimento & 1,0 & $3,0 \mathrm{Ba}$ & $3,0 \mathrm{Aa}$ \\
do Hipocótilo & 4,0 & $35,0 \mathrm{Aa}$ & $25,0 \mathrm{Ab}$ \\
\hline
\end{tabular}

Médias seguidas de letras iguais, maiúscula na coluna e minúscula na linha, para cada bioensaio, não diferem pelo teste de Tukey (5\%). da planta analisado. As inibições observadas, em todos os bioensaios, variaram $(p<0,05)$ positivamente com o aumento da concentração do extrato aquoso, com inibições máximas observadas na concentração de $4,0 \%$. Os efeitos alelopáticos inibitórios efetivados sobre a espécie malícia foram de maior magnitude em relação àqueles verificados sobre mata-pasto, sendo as diferenças entre as duas espécies de maior expressão nos bioensaios de germinação e de desenvolvimento da radícula.

Independentemente da espécie receptora e da concentração, as inibições promovidas sobre o desenvolvimento da radícula estiveram acima dos $50 \%$ para malícia e dos $30 \%$ para mata-pasto, bem superiores àquelas verificadas sobre a germinação de sementes ou desenvolvimento do hipocótilo das duas plantas receptoras, indicando o desenvolvimento da radícula como fator da planta mais sensivel aos efeitos alelopáticos.

Considerando a inibição mínima de 50\% como padrão satisfatório para avaliar as potencialidades alelopáticas de um dado extrato (Dudai et al., 1999), inibições dessa ordem foram obtidas sobre o desenvolvimento da radícula da espécie malícia, nas duas concentrações estabelecidas, e de mata-pasto na concentração de 4,0\%. Outras inibições, embora abaixo de $50 \%$, merecem destaque, como as observadas sobre a germinação das sementes de malícia (40\%) e o desenvolvimento da radícula de mata-pasto, na concentração de 1,0\% (35\%).

No conceito de alelopatia estão embutidos dois tipos de efeitos, que são os deletérios e os estimulatórios (An et al., 1993), conquanto a literatura documente mais os efeitos inibitórios. Aparentemente, os efeitos estimulatórios estão relacionados à concentração, manifestando-se em condições de baixa concentração (Rice, 1984). No presente trabalho, mesmo em concentração tão baixa quanto $1,0 \%$, não foram observados efeitos estimulatórios em qualquer dos bioensaios desenvolvidos. Aparentemente, a concentração mínima estabelecida neste trabalho está acima daquela requerida para promoções de efeitos estimulatórios.

Fusarium solani e outras espécies de Fusarium, pertencentes ao grupo Martiella, produzem várias toxinas com estrutura naftazarina comum. Seis substâncias químicas 
com diferentes grupos funcionais e atividades biológicas já foram isoladas, como novarubina, norjavanicina, javanicina, fusarubina, marticina e isomarticina (Kern, 1972; Drysdale, 1984). Aparentemente, os resultados obtidos neste trabalho são conseqüência da ação isolada de uma dessas toxinas ou, então, o resultado líquido da ação conjunta de todas elas, ou mesmo de outra substância ainda por ser isolada e identificada.

\section{LITERATURA CITADA}

AMAGASA, T. et al. Physiological effects of cornexistin on Lemma pausicostata. Pestic. Biochem. Physiol., v. 49, n. 1, p. 37-52, 1994.

AN, M.; JOHNSON, I. R.; LOVETT, J. V. Mathematical modeling of allelopathy: biological response to allelochemicals and its interpretation. J. Chem. Ecol., v. 19, p. 2379-2389, 1993.

ANAYA, A. L. Allelopathy as a tool in the management of biotic resources in agroecosystems. Critical Rev. Plant Sci., v. 18 , n. 6 , p. $697-739,1999$.

CHRISTOFFOLETI, P. J. Curvas de dose-resposta de biótipos resistentes de Brachiaria plantaginea a herbicidas inibidores da ACCase. R. Bras. Herb., v. 2, n. 3, p. 87-91, 2001.

CHRISTOFFOLETI, P. J.; VICTORIA FILHO, R.; SILVA, C. B. Resistência de plantas daninhas aos herbicidas. Planta Daninha, v. 12, n. 1, p. 13-20, 1994.

CUTLER, H. G. Perspective on discovery of microbial phytotoxins with herbicidal activity. Weed Technol., v. 2, p. 525-532, 1988.

DRYSDALE, R. B. The production and significance in phytopathology of toxins produced by species of Fusarium. In: MOSS, M. O.; SMITH, J. E. (Ed.). The applied mycology of Fusarium. Cambridge: University Press, 1984. p. 95-105.

DUARTE, M. L. R.; ARCHER, S. A. In vitro toxin production by Fusarium solani f. sp. piperis. Fitopatol. Bras., v. 28, n. 3, p. 229-235, 2003.

DUDAI, N. et al. Essential oils as allelochemicals and their potential use as bioerbicides. J. Chem Ecol., v. 25, n. 5, p. 1079-1089, 1999.

DUKE, S. O.; ABBAS, H. K. Natural products with potential use as herbicides. In: INDERKIT; DAKSHINI, K. M. M.; EINHELLIG, F. A. Allelopathy: organism, processes and applications. Washington: American Chemical Society, 1995. p. 348-362. (ACS. Symposium Series, 582).
DUKE, S. O.; ROMAGNI, J. G.; DAYAN, F. E. Natural products as sources for new mechanisms of herbicidal action. Crop Prot., v. 19, p. 583-589, 2000.

DUKE, S. O. et al. Chemical from nature for weed management. Weed Sci., v. 50, n. 2, p. 138-151, 2002.

GERWICK, B. C. et al. Pyridazocidin, a new microbial phytotoxin with activity in the mehler reaction. Weed Sci., v. 45 , p. 654-657, 1997.

JASIENIUK, M.; BRÛLÉ-BABEL, A.; MORRINSON, I. N. The evolution and genetics of herbicide resistance in weeds. Weed Sci., v. 44, n. 1, p. 176-193, 1996.

HEAP, I. The occurrence of herbicide-resistant weeds worldwide. Pestic. Sci., v. 51, p. 235-243, 1999.

HOAGLAND, R. E. Microbes and microbial products as herbicides: an overview. In: HOAGLAND, R. E. (Ed.). Microbes and microbial products as herbicides. Washington: ACS Books, 1990. p. 2-52. (American Chemical Society. Symposium Series, 439).

KERN, H. Phytotoxins produced by Fusaria. In: WOOD, R. K. S.; BALILI, A.; GRANNITI, A. (Eds.). Phytotoxins in plant disease. New York: Academic Press, 1972. p. 35-48.

LOPES-OVEJERO, R. F. et al. Resistência de populações de capim-colchão (Digitaria ciliares) aos herbicidas inibidores da acetil Co-A carboxilase. Planta Daninha, v. 23, n. 3, p. 543-549, 2005.

METHA, Y. R.; BROGNIN, R. L. Phytotoxicity of a culture filtrate produced by Stemphylium solani of cotton. Plant Disease, v. 84, p. 838-842, 2000.

RICE, E. L. Allelopathy. New York: Academic Press, 1984. $422 \mathrm{p}$.

ROMAGNI, J. G.; ALLEN, S. N.; DAYNAN, F. E. Allelopathic effects of volatile cineols on two weeds plant species. J. Chem. Ecol., v. 26, n. 1, p. 303-313, 2000 a.

ROMAGNI, J. G.; DUKE, S. O.; DAYAN, F. E. Inhibition of asparagine synthetase by 1,4-cineol, the key to the mode of action of cinmethylin. Plant Physiol., v. 123, p. 725-732, $2000 \mathrm{~b}$.

SAS - INSTITUTE. Statistical Analysis System. User's guide. Version 6. 4.ed. Cary: 1989. 846 p.

STROBEL, G. et al. Phytotoxins as potential herbicides. Experientia, v. 47, p. 819-826, 1991.

VIDAL, R. A. Herbicidas: mecanismos de ação e resistência de plantas daninhas aos herbicidas. Porta Alegre: Universidade Federal do Rio Grande do Sul, 1997. 165 p.

VIDAL, R. A. et al. Similaridade genética entre acessos de Bidens pilosa resistentes aos herbicidas inibidores da ALS. Planta Daninha, v. 23, n. 3, p. 551-556, 2005. 